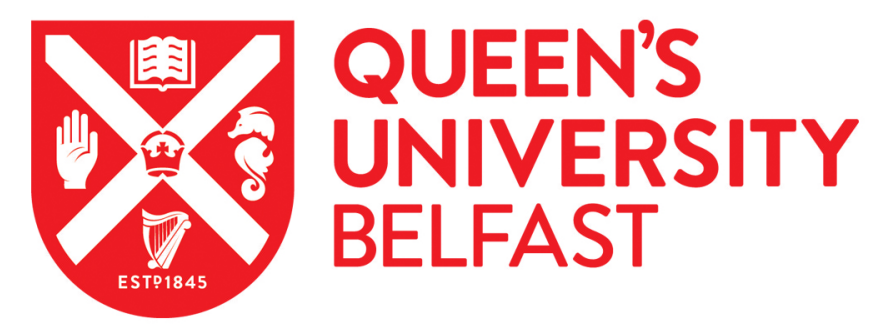

\title{
Traumatic brain injury and social competence among young male offenders
}

Linden, M., O'Rourke, C., \& Lohan, M. (2019). Traumatic brain injury and social competence among young male offenders. Disability and Rehabilitation. https://doi.org/10.1080/09638288.2019.1629699

Published in:
Disability and Rehabilitation

Document Version:

Peer reviewed version

Queen's University Belfast - Research Portal:

Link to publication record in Queen's University Belfast Research Portal

Publisher rights

( 2019 Taylor and Francis. This work is made available online in accordance with the publisher's policies. Please refer to any applicable terms of use of the publisher.

\section{General rights}

Copyright for the publications made accessible via the Queen's University Belfast Research Portal is retained by the author(s) and / or other copyright owners and it is a condition of accessing these publications that users recognise and abide by the legal requirements associated with these rights.

Take down policy

The Research Portal is Queen's institutional repository that provides access to Queen's research output. Every effort has been made to ensure that content in the Research Portal does not infringe any person's rights, or applicable UK laws. If you discover content in the Research Portal that you believe breaches copyright or violates any law, please contact openaccess@qub.ac.uk. 
Accepted for publication 05/06/2019; Disability \& Rehabilitation.

TITLE: Traumatic brain injury and social competence among young male offenders.

Running head: Traumatic brain injury and young offenders

\section{ABSTRACT}

Purpose: To investigate the prevalence of Traumatic Brain Injury (TBI) among young incarcerated males and determine the extent of deficits in behavioural regulation, aggression, hopelessness and perceived social support, compared to a control group of non-incarcerated males. Methods: Sixtytwo young offenders and fifty-eight university-based, gender-matched controls agreed to take part. We collected information on criminal history, risk taking behaviour, drug and alcohol abuse and mental illness. In addition, we employed measures of Brain Injury, Hopelessness, Behavioural Regulation, Aggression and Perceived Social Support. Results: Just over $87 \%(n=54)$ of offenders exhibited some level of TBI with over 31\% ( $n=17)$ reporting 6 or more injuries. Offenders with TBI exhibited poorer behavioural control ( $\mathrm{p}<.001 ; \mathrm{M}=66.01 \mathrm{Vs}$. $\mathrm{M}=51.33 ; 95 \% \mathrm{Cl}-19.08$ to -11.76$)$, higher levels of aggression ( $p<.001 ; M=101.19$ Vs. $M=69.39 ; 95 \% \mathrm{Cl}-38.31$ to -27.17 ) and higher levels of hopelessness ( $p<.001 ; M=5.65 \mathrm{Vs} . \mathrm{M}=2.55)$ when compared to controls with TBI. Severity of TBI correlated positively with behavioural regulation, aggression and hopelessness. Conclusions: Greater recognition of the presence and consequences of TBI within the custodial estate is necessary if the needs of young offenders are to be adequately met. Young offenders with TBI experience heightened vulnerability and need rehabilitative input to support their time in prison and on their return to society.

Keywords: traumatic brain injury; young offenders; behavioural regulation; aggression; hopelessness.

\section{Introduction}

There is increasing awareness that the prevalence of Traumatic Brain Injury (TBI) among offender populations is many times that seen in members of the general public ( $25 \%$ to $87 \%$ compared to 8.5\%) (1-3). Traumatic brain injury is defined as an insult to the brain by an external force that disrupts the normal functioning of the brain (4). These injuries occur after birth and can have significant and life-long consequences including deficits in memory, attention, emotion, language and behavioural control (5-7). Males are between 1.2 to 4.6 times more likely to sustain a TBI compared to females (4) with the primary mechanism of injury for young people (aged 15-19 years) being road traffic accidents (8). Traumatic brain injury therefore represents a major health concern for those working within Criminal Justice. 
Accepted for publication 05/06/2019; Disability \& Rehabilitation.

Brain maturation occurs from birth until our early twenties with the frontal lobes being the last to fully develop (9). As such, these regions are more vulnerable to childhood injury which may mean that an individual does not fully develop the ability to regulate their behaviour (10). Frontal lobe dysfunction and deficits in behavioural regulation can mean that an individual possesses poor impulse control, planning, organisation, behavioural and emotional control and reduced ability to monitor the consequences of their actions $(11,12)$. Such deficits mean that young male survivors of $\mathrm{TBI}$ are at a heightened risk of engaging in antisocial and criminal behaviour.

Brain injury is a hidden disability which often goes unreported (13). Classified as mild, moderate or severe, only those injuries which require hospitalisation are likely to receive a diagnosis of brain injury (e.g. moderate or severe injuries). Concussions or mild traumatic brain injuries (mTBI) are the most common type of injury which make up around $80 \%$ of all cases (14). In most instances, symptoms following mTBI resolve after 2-3 months, however there is increasing evidence that long term deficits in behaviour, memory and depression can result from single or multiple cases of mTBI $(10,15-17)$. Due to the developmental maturation of the brain, injuries which occur in childhood may not become apparent until the brain has fully developed. This means that the cause (i.e. TBI) and event (i.e. impulsivity, aggression, academic decline) may be separated by many years, making a diagnosis of TBI extremely challenging. Therefore, young offenders, their families, probation services and the court may not be aware that antisocial behaviour may be partially explained by the presence of a TBI. Members of probation services have been shown to hold misconceptions about brain injury which has implications for the proper identification, sentencing and rehabilitation of offenders (18). Young offenders experience heightened vulnerability due their often complex presentation. Many come from disadvantaged backgrounds, have family members or parents serving custodial sentences, have substance abuse problems and possess poor mental health (19-21). Within the custodial estate, offenders with TBI have been shown to have higher rates of infractions than offenders without TBI which have been attributed to higher levels of aggression (22). Prisoners with $\mathrm{TBI}$ are at a significantly heightened risk of mental illness (23-25) with increased aggression and behavioural problems serving to increase their isolation and vulnerability. The removal of liberty and contact with loved ones leads to reduced social support and increased isolation, which is a contributory factor towards poor mental health (26). To date, no studies have explored the link between TBI, social support and mental illness or hopelessness among young offenders. A lack of understanding about the interplay between these factors may mean that those working within the custodial estate fail to recognise and support the most vulnerable in their care. Researchers have questioned whether the custodial estate offers suitable rehabilitation for individuals who lack clear 
Accepted for publication 05/06/2019; Disability \& Rehabilitation.

understanding of the consequences of their actions and who experience cognitive and behavioural difficulties (27).

The aim of the current project was to explore the prevalence of TBI among young offenders and determine the extent of impairments in areas of behavioural regulation, aggression, hopelessness and perceived social support. Together we refer to these factors as social competence in keeping with the heuristic model of social cognition described by Yeates et al. (28). If young offenders experience significant impairments in areas of social competence as the result TBI, it may partly explain their involvement with criminal justice and may suggest possible avenues for services to provide targeted rehabilitation.

\section{Method}

Design

A cross-sectional structured interview design was employed with the aim of comparing social competence outcomes across three groups; offenders with TBI, offenders without TBI, and nonincarcerated controls. However, significantly high rates of injury amongst offenders resulted in low recruitment of offenders without TBI. It was therefore not possible to include a comparison group of offenders without injury. A large number of recruited controls also reported past TBI with significant within group differences noted in behavioural regulation $(t(56)=2.180, p=.033)$ and aggression $(t(56)=2.082, p=.042)$. To ensure comparability between offenders with TBI $(n=54)$ and controls, only controls with TBI $(n=33)$ were included in the analyses of behavioural regulation, aggression, hopelessness and perceived social support.

Ethical approval was granted by a regional Health and Social Care research ethics committee (ref: 15/NI/0011) with additional approvals granted from the Department of Justice and prison governor's office.

\section{Participants}

A sample of 103 young (aged 18-21 years) male offenders, held at a young offenders centre in the UK, were approached to take part in this study, with 62 (60\%) agreeing to take part. There were no set inclusion criteria, though participants who could not understand or speak English were excluded. Gender-matched non-incarcerated controls were recruited from a university population. This population was selected due to convenience and accessibility. Though effort was made to recruit age matched control participants, this was not possible and within the final sample, controls (Mean age= 21 years) were significantly older than offenders (Mean age $=19$ years). Control participants were excluded if they had been previously incarcerated. 
Accepted for publication 05/06/2019; Disability \& Rehabilitation.

\section{Measures}

The Brain Injury Screening Index (29) contained 7 items and was used to detect historic instances of TBI. Participants are asked to report the number of times in which they have received a serious blow to the head that resulted in a loss of consciousness or where afterwards they felt dazed and confused. The severity of each injury is examined, alongside information on the actions taken after the incident e.g. attended hospital. The BISI can be scored to produce a TBI Severity Index score (018) by multiplying the highest rate of unconsciousness (0-3) by the number of TBIs (0-6).

The Beck Hopelessness Scale (BHS) (30), comprised 20 self-report items and examines negative expectancies. High levels of perceived hopelessness can result in a reduction in goal-striving behaviour which correlates highly with depressive symptoms (30). It has proven reliability and internal consistency (31).

The Behaviour Regulation Index (BRI) from the Behaviour Rating Inventory of Executive Function Adult version (BRIEF-A) (32), was used to assess participants' ability to control their behavioural and emotional responses. The BRI contains 30 items comprising the Inhibit, Shift, Emotional Control, and Self-Monitor subscales. Participants respond on a three-point scale comprising "Never", "Sometimes", or "Often". Responses are summed to produce total and subscale scores. The validity and reliability of the BRIEF-A has been well established and has been successfully employed in a range of clinical populations (32).

The Buss-Perry Aggression Questionnaire (BPAQ) (33) consists of 29 items covering four subtraits of aggression; physical, verbal, anger and hostility. Participants are asked to respond on a five-point Likert scale where 1 represents "extremely uncharacteristic of me"' and 5 represents "extremely characteristic of me". The questionnaire has been shown to possess moderate to high levels of internal consistency and construct validity (34).

The Multidimensional Scale of Perceived Social Support (MSPSS) (35) is a 12-item self-report instrument designed to assess perceived social support from family, friends, and significant others. Participants are asked to respond on a seven-point Likert scale where 1 represents "Very Strongly Disagree" and 7 represents "Very strongly Agree". The measure has proven reliability and validity (36).

Participant demographics included; age, number of criminal convictions, age at first offence, past risky or illegal behaviours, past medical and mental health diagnoses, medication, education, and maternal education. Current criminal convictions were dichotomized into violent (e.g. assault, murder, rape) and nonviolent (e.g. theft, drug possession, fraud) crimes in line with the Crime Survey 
Accepted for publication 05/06/2019; Disability \& Rehabilitation.

for England and Wales guidelines (37). Participants were subsequently asked to indicate whether they had ever engaged in six victim-based crimes; physical/threatened assault, dangerous acts endangering persons, robbery (including attempted), sexual assault and related offences, murder and related offences, abduction/harassment. These were adapted from the Australian and New Zealand Standard Offence Classification, based upon their ease of use and ability to provide a broad overall picture of crimes committed against a person within a limited number of categories (38). Maternal education was used as a proxy measure for socio-economic status (SES) in line with past research $(39,40)$ dichotomised as low (primary school, GCSE, apprenticeship, certificate/diploma) and high (A-levels, university degree, postgraduate degree). Reporting of past mental health diagnoses or prescription of anti-depressant medication was used to record past mental illness. Finally, two questions assessed whether participants had ever been told they had a brain injury, or whether they thought they had a brain injury.

\section{Procedure}

Recruitment posters explaining the intentions of the research were distributed throughout the prison. Approximately 2-3 weeks later, potential participants were approached and invited to take part. Offenders were given information sheets and had the chance to ask questions about the research before taking part. Participants provided their name and identification number to the researcher which were forwarded to the prison bookings department to arrange interview times.

Given the poor literacy levels of young offenders (41), data was obtained by face to face interview. This method was chosen to maximise the completion of questionnaire items and to aid with misunderstanding. Participants were taken to a quiet room and invited to read and complete the consent form and questionnaire at their own pace, or have the questions read aloud to them.

Non-incarcerated control participants, matched on gender and age, were drawn from a university population. Control participants were sent an email invitation. Those interested in participating were asked to email the researcher who arranged a suitable time for testing. Upon meeting, control participants completed the consent form and questionnaires.

\section{Data Analysis}

Data were analysed using SPSS version 22 (42). Demographic data was compared across all participants ( $n=120$ ) stratified by group (offenders vs controls). Where appropriate, distribution of data was assessed using Shapiro-Wilk tests. Group differences were examined using a combination of t-tests and Mann-Whitney $U$ tests, where appropriate. Spearman's rho assessed the relationship between TBI Severity Index scores and select measures for all offenders ( $n=62)$, while multiple linear regression examined the factors predictive of BRI scores. 
Accepted for publication 05/06/2019; Disability \& Rehabilitation.

\section{RESULTS}

\section{Demographic and clinical findings}

Demographic and clinical information on offenders $(n=62)$ and controls $(n=58)$ is displayed in Table 1. Differences were noted for all variables including, age, education, maternal education, number and severity of TBI, past drug and alcohol abuse, and mental illness. TBI was more prevalent among offenders than controls, as was drug abuse, alcohol abuse, and mental illness. The majority of offenders $(69 \%, n=43)$ had committed a violent offence, with the mean age of first offence at 14.8 years. Many offenders reported having engaged in assault $(80.6 \%, n=50)$, dangerous acts endangering others $(62.9 \%, n=39)$, or robbery $(56.5 \%, n=35)$, while a notable number had engaged in murder and related offences $(12.9 \%, n=8)$. Offenders also reported engaging in risky behaviour at a significantly younger age than controls. Half of offenders $(50 \%, n=31)$ reported primary school as their highest level of education. Despite a large number of offenders not knowing their mothers' education level $(27 \%, n=17), 78 \%(n=35)$ of the remainder reported an education level which indicated a low SES background.

Insert table 1 about here

\section{History of TBI}

Prevalence rates were high for both groups, with $87 \%$ of offenders $(n=54)$ and $56.9 \%$ of controls $(n=33)$ reporting past TBI. The profile of injury differed between groups however, with prevalence rates falling to $70 \%(n=44)$ among offenders, and $25.8 \%(n=15)$ among controls when Loss of Consciousness (LOC) was taken into account. The majority of injuries were mild for both groups, with only one control participant reporting a moderate injury. Among offenders with TBI $40 \%$ ( $n=22$ ) reported a past injury in the moderate to severe range. Similarly, offenders reported experiencing many more injuries than controls, with $31.5 \%(n=17)$ reporting $6+$ injuries compared to $9 \%(n=3)$ of controls. A total of 250 TBI incidents were recorded, 184 among offenders and 66 among controls. Of the 250 total incidents (offenders and controls) of TBI, only 94 (37.6\%) were treated in hospital, with 139 (56\%) receiving no subsequent care. Awareness of past injury was assessed using two questions; "Have you ever been told you have a brain injury?" "Do you think you have a brain injury?" Of the participants who screened positive for TBI, only 3 offenders and 2 controls reported ever being told they had an injury. In contrast, only 12 offenders and one control with TBI believed themselves to have a brain injury. 
Accepted for publication 05/06/2019; Disability \& Rehabilitation.

\section{Substance abuse and mental illness}

Rates of past drug (80.6\%) and alcohol abuse (54.8\%) were high among offenders. TBI Severity Index scores $(U=153, p=.008)$ alongside total aggression $(t(60)=3.11, p=.003 ; 95 \% \mathrm{Cl} 5.45$ to 25.07$)$, behavioural regulation $(U=81, p<.001)$, and hopelessness $(U=99, p=.001)$ scores were significantly higher among offenders with past drug abuse $(n=50)$ than those without $(n=12)$.

Mental illness, including depression, anxiety, bi-polar disorder, paranoid schizophrenia, and PTSD were prevalent among offenders (58.1\%). TBI Severity Index scores were significantly higher among offenders with a reported mental illness ( $n=37)$ compared to offenders without $(n=25)(U=320$, $\mathrm{p}=.032)$, as was total aggression $(\mathrm{t}(60)=2.994, \mathrm{p}=.004 ; 95 \% \mathrm{Cl} 3.90$ to 19.61$)$, behavioural regulation $(t(60)=2.7, p=.005 ; 95 \% \mathrm{Cl} 2.38$ to 12.54$)$, and hopelessness $(U=250, p=.034)$. The presence of dual conditions was also noted, with $51.6 \%(n=32)$ of offenders reporting co-occurring drug abuse and mental illness.

\section{Social Competence}

As noted previously, given the lack of available offenders without TBI, comparison of social competence outcomes between offenders with and without TBI was not possible. Offenders with TBI $(n=54)$ were thus compared to controls with TBI $(n=33)$ to establish whether incarceration status impacted social competence outcomes. Table 2 provides a summary of the mean total and subscale scores for each of the four included measures of social competence.

\section{Insert table 2 about here}

Offenders with TBI displayed significantly poorer behavioural regulation than controls on both total $(t(85)=-6.986, p<.001 ; 95 \% \mathrm{Cl}-19.08$ to -11.76$)$ and subscale scores of the BRI. Total mean scores were around 15 points higher for offenders, suggesting significant differences in how offenders with TBI monitor and regulate their emotions, behaviours, and thinking. Similarly with aggression, total scores on the BPAQ were significantly higher among offenders than controls $(t(85)=-9.921, p<.001$; $95 \% \mathrm{Cl}-38.31$ to -27.17$)$. While all subscale scores were also significantly higher for offenders, the largest differences were seen in mean physical aggression (Mean= 35 vs 21) and anger (Mean= 25 vs 16) scores. The significant difficulties observed in behavioural and emotional regulation likely contribute to this heightened aggression. Significantly higher rates of hopelessness were also noted among offenders with TBI $(U=332.5, p<.001)$. Incarceration, low SES and significant rates of mental illness are likely explanations. While total perceived social support was not significantly different between groups, perceptions of familial support were significantly lower among offenders with TBI relative to controls $(U=615, p=.049)$. 
Accepted for publication 05/06/2019; Disability \& Rehabilitation.

\section{TBI severity and social competence}

To examine the relationship between TBI severity and social competence scores, Spearman's rho correlations were conducted with all offender data $(n=62)$ for behavioural regulation, aggression and hopelessness scores. TBI Severity Index scores correlated positively with behavioural regulation $(r=.418, p=.001)$, aggression $(r=.384, p=.002)$, and hopelessness $(r=.369, p=.006)$ suggesting that as TBI Severity Index scores increase, so too does aggression, feelings of hopelessness, and poorer behavioural regulation.

A multiple linear regression was subsequently conducted to establish whether a combination of greater TBI Severity Index scores, alongside presence of mental illness and past drug abuse, contributed to behavioural regulation scores among offenders $(n=62)$. The final model was significant $[F(3,58)=8.99, p<.001]$, with a multiple correlation coefficient of .56 , and approximately $32 \%$ of the variation in BRI scores accounted for. Examination of the individual variables revealed that while past drug abuse was predictive of BRI total score $(\beta=9.46, p=.003)$, TBI Severity Index scores only approached significance $(\beta=.5, p=.065)$ and past mental illness was non-significant $(\beta=$ $3.83, p=.118)$.

\section{Discussion}

TBI was highly prevalent among both young offenders (87.1\%) and controls (56.9\%). Differences in both definitions and measurement of TBI have resulted in significant variance in reported prevalence rates between studies (24). This study employed the BISI, one of only three known screening tools which have been validated for use among offender groups. When compared to other studies utilising similarly validated measures, the prevalence rate of $87.1 \%$ in the current study is higher $[78 \%,(43)$; $65 \%,(44) ; 64.1 \%,(45)]$, however it is comparable to that of other researchers [88\% (2); $87 \%(1)]$. These disparities may have resulted from differences in recruitment and sample sizes. It is also possible that individuals were more likely to take part if they recalled experiencing head injuries, thus inflating the prevalence rate. Among those who did take part almost a third (31.5\%) reported $6+$ injuries. One of the benefits of administering the BISI through structured interview was that it allowed offenders to question whether certain incidents (particularly those without LOC) counted as TBIs. In this way, a large number of injuries were recorded for which no post-TBI care was sought. While over half of the offenders with TBI (51.6\%) indicated that their most severe injury was mild, the potential cumulative effects of such repeat mild injuries warrants concern, particularly if these were not medically assessed. 
Accepted for publication 05/06/2019; Disability \& Rehabilitation.

Despite high rates of injury, awareness was low for both offenders and controls. Only three offenders reported ever being told they had a brain injury, with only two of these choosing to believe this. This overall lack of recognition of TBI likely affects an offender's propensity to seek medical treatment and may be the reason so many injuries go unidentified. Overall knowledge and awareness of TBI is likely also a factor, given the number of individuals who could recall multiple injuries, yet failed to identify these as possibly resulting in brain injury. Misconceptions and a lack of knowledge around TBI are common, and can be found across many different populations, from the general public $(46,47)$, to healthcare professionals $(48,49)$ and educators $(50)$. The vulnerability of offenders, particularly considering possible learning and comprehension difficulties, suggests the need for those involved in their care to be proactive in identifying and communicating issues around TBI.

\section{Social competence}

Offenders with TBI displayed significantly poorer self-regulation, alongside greater levels of aggression and perceived hopelessness. Among all offenders ( $n=62$ ), TBI Severity Index scores correlated positively with aggression, poor behavioural regulation and hopelessness, suggesting that those with a greater number of more severe injuries present with the greatest impairments. Poor self-control coupled with high levels of aggression are suggestive of significant social difficulties. In line with the Heuristic Model of Social Competence (28), difficulties in evaluating social contexts, correctly interpreting social cues, and generating appropriate responses may place significant strain on an individual when faced with stressful situations. Such frustration and difficulty may be expressed in the form of anger, aggression, and violence. Both outside and within the prison environment, such deficits may serve to not only drive away peers, but lead to greater confrontation with friends, family and those in authority. Such a combination may also pose significant problems when working with prison staff and services. Aggressive behaviours and violent outbursts, often associated with $\mathrm{TBI}$, can cause significant problems for staff attempting to provide rehabilitative or medical services (51).

Offenders with higher TBI Severity Index scores also displayed significantly higher rates of hopelessness. The BHS reflects negative self-perceptions regarding the future which have been shown to act as an impediment to peer acceptance, leading individuals to withdraw from social interaction (28). Hopelessness has also been described as a pre-cursor to suicidal ideation and is more predictive of future risk of suicide than measures of depression (52). With self-harm and suicide representing a significant problem among offenders (53), recognising the potential role of TBI is crucial to identification and treatment of at-risk individuals. The present study showed that $56.5 \%$ of young offenders had some difficulties with mental health. TBI Severity Index scores alongside 
Accepted for publication 05/06/2019; Disability \& Rehabilitation.

measures of behavioural regulation, aggression, and hopelessness were significantly poorer among those with a mental illness. As such, young male offenders with TBI may face greater struggles in developing and maintaining supportive relationships with those around them. Given the focus on addressing mental health and suicide within prisons, it is necessary not only to consider the provision of services, but also their accessibility and suitability for individuals with TBI.

\section{Comorbidities}

In addition to high rates of TBI, the complexity of need among young offenders was evident.

Offenders reported engaging in risky behaviours at a significantly younger age than non-incarcerated controls. While over half of the offender sample reported past alcohol abuse (54.8\%), 80\% reported past drug abuse. Drug abuse is a widely recognised issue among offender groups (54-56), with $16 \%$ of young men reporting having developed a drug problem while in prison (57). Drug and alcohol abuse can have wide ranging health, economic, and social consequences for an individual (58). Drug abuse can adversely impact on brain development and result in reduced pre-frontal and hippocampal volumes, executive functioning problems, and depressive symptoms (59). Intoxication at time of injury has been associated with greater severity and substance abuse has been shown to complicate recovery from TBI (60). In the present study, past drug abuse was associated with higher TBI Severity Index scores, poorer behavioural regulation, greater aggression, and more severe levels of hopelessness among offenders. Such complicated presentations may serve to overshadow or mask TBI related problems and exacerbate the effects of injury. In attempting to draw links between $\mathrm{TBI}$ and offending behaviour, the centrality of substance abuse in understanding crime cannot be overlooked.

Offenders represent a group of individuals who present with a complex interplay of many conditions. Studies have highlighted alarming rates of mental and health problems including depression, learning difficulties, oppositional defiant/conduct disorder and attention deficit hyperactivity disorder (Bradley, 2009; Fazel, Doll, \& Långström, 2008; McKinlay, Grace, Horwood, Fergusson, \& MacFarlane, 2010) within this population. It is therefore difficult to determine whether brain injury has caused these comorbidities or whether having a condition like ADHD may result in a greater risk of acquiring a brain injury. Whatever the cause and effect nature of this relationship is the presence of brain injury among offenders must be recognised and treated if these individuals are to receive equitable and effective care within the custodial estate.

Researchers have called for those who regularly interact with offenders, to offer support and promote adaptive coping strategies $(3,18,61)$. Improved training and awareness raising around TBI for criminal justice staff appears essential given the high rates of injury observed within this 
Accepted for publication 05/06/2019; Disability \& Rehabilitation.

population. With increased awareness, staff would be well placed to identify and direct offenders to healthcare teams and reduce stigmatisation. With a better understanding of the behavioural and social difficulties experienced by an individual with TBI, prison staff may be better able to empathise and subsequently support those under their care.

\section{Limitations}

These results must be considered in light of several limitations. Self-selection bias may have contributed to the very high prevalence rate of TBI across both samples. Despite the fact that many participants did not recognise their injuries as TBIs, recruitment often involved explaining that the study was interested in people who had experienced "Knocks or blows to the head". The use of selfreport in both TBI screening and outcome measurement is not ideal and may have adversely impacted results. Self-report of TBI is prone to both under-reporting and false recall of incidents particularly for injuries at younger ages (25), however, research suggests offender self-report of TBI is generally accurate (62). Participants in the control group were older and more highly educated that those in the offender group. In addition, the self-selecting nature of our sample meant that control participants may have been motivated to participate due to personal interest resulting in some degree of selection bias. It was not possible to recruit sufficient numbers of young offenders without brain injury, the ideal group for comparison. However, our control group did have the relative advantage of having a high degree $(57 \%, n=33)$ of injury, albeit predominantly in the mild range. Due to logistical issues within the prison, a number of offenders could not be accessed for recruitment. The challenges of working within the custodial estate meant that staff shortages often restricted the free time available to offenders, meaning recruitment windows were narrow and not all offenders were available. Last minute schedule changes, security risks, and the demands of other services created barriers to recruitment.

\section{Conclusions}

The significantly high rates of both TBI and TBI with LOC identified among offenders indicates a substantial health need within this group. Healthcare professionals working within the criminal justice system (CIS) should consider not only the presence of injury, but both the number of repeat injuries, and severity, which may have a cumulative effect. Few offenders recognised themselves as having a TBI. Reliance on offenders themselves to both understand and communicate the extent of their injuries will likely lead to many TBIs remaining hidden. The lack of knowledge and awareness of TBI emphasises the need for greater effort on the part of the CJS to identify and support such individuals. Criminal justice has a duty of care to offenders and should ensure that individuals fully 
Accepted for publication 05/06/2019; Disability \& Rehabilitation.

understand both the presence of their TBIs and their potential impact on behaviour. Members of the CJS require access to training on the identification, causes and consequences of TBI.

Recognising the interconnectedness of TBI, drug abuse, and mental illness may help ensure that offenders with particularly complicated presentations do not "fall through the cracks" of services. Existing and future programmes which aim to address mental illness or substance abuse within this group should be aware of deficits in social competence which could substantially hamper access and engagement with these programmes. Both prison officers and healthcare staff should be aware of possible indicators of injury, such as social exclusion, confrontational behaviour, and difficulties regulating behaviour and emotions in stressful situations.

The highly structured nature of prison life may be of benefit to young offenders with behavioural regulation difficulties. Problems appear when these young men leave this environment and are expected to reintegrate back into society. Without adequate recognition and support of such deficits it is unsurprising that many young offenders enter into patterns of behaviour which lead to repeat involvement with the CJS. By investing in training for staff and the provision of support for young offenders, both within the CJS and on leaving, we could cut rates and costs of recidivism and significantly improve the lives of these young men.

\section{Declaration of interest}

The authors report no conflicts of interest.

\section{References}

1. Slaughter B, Fann JR, Ehde D. Traumatic brain injury in a county jail population: prevalence, neuropsychological functioning and psychiatric disorders. Brain Inj [Internet]. 2003 Sep [cited 2014 Aug 15];17(9):731-41. Available from: http://www.ncbi.nlm.nih.gov/pubmed/12850940

2. Diamond PM, Harzke AJ, Magaletta PR, Cummins a G, Frankowski R. Screening for traumatic brain injury in an offender sample: a first look at the reliability and validity of the Traumatic Brain Injury Questionnaire. J Head Trauma Rehabil. 2007;22(6):330-8.

3. Hughes N, Williams WH, Chitsabesan P, Walesby RC, Mounce LTA, Clasby B. The prevalence of traumatic brain injury among young offenders in custody: A systematic review. J Head Trauma Rehabil. 2015;30(2):94-105. 
Accepted for publication 05/06/2019; Disability \& Rehabilitation.

4. Peeters W, van den Brande R, Polinder S, Brazinova A, Steyerberg EW, Lingsma HF, et al. Epidemiology of traumatic brain injury in Europe. Acta Neurochir (Wien). 2015;157(10):168396.

5. Anderson V, Catroppa C, Morse S, Haritou F, Rosenfeld J. Attentional and processing skills following traumatic brain injury in early childhood. Brain Inj. 2005;19(9):699-710.

6. Catroppa C, Anderson VA, Muscara F, Morse SA, Haritou F, Rosenfeld J V, et al. Educational skills: long-term outcome and predictors following paediatric traumatic brain injury.

Neuropsychol Rehabil [Internet]. 2009 Oct [cited 2014 Mar 28];19(5):716-32. Available from: http://www.ncbi.nlm.nih.gov/pubmed/19306233

7. Hawley $C A$, Ward AB, Magnay AR, Mychalkiw W. Return to school after brain injury. Arch Dis Child [Internet]. 2004 Feb 1 [cited 2014 Mar 28];89(2):136-42. Available from: http://adc.bmj.com/cgi/doi/10.1136/adc.2002.025577

8. Faul M, Xu L, Wald MM, Coronado VG. Traumatic brain injury in the United States: emergency department visits, hospitalizations, and deaths. Centers Dis Control Prev Natl Cent Inj Prev Control [Internet]. 2010;891-904. Available from:

http://www.ncbi.nlm.nih.gov/pubmed/23630120

9. Toga AW, Thompson PM, Sowell ER. Mapping brain maturation. Trends Neurosci. 2011;29(3):148-59.

10. Vynorius KC, Paquin AM, Seichepine DR. Lifetime Multiple Mild Traumatic Brain Injuries Are Associated with Cognitive and Mood Symptoms in Young Healthy College Students. Front Neurol [Internet]. 2016;7(October):5-10. Available from:

http://journal.frontiersin.org/article/10.3389/fneur.2016.00188/full

11. Levin HS, Hanten G. Executive functions after traumatic brain injury in children. Pediatr Neurol [Internet]. 2005 Aug [cited 2014 Apr 3];33(2):79-93. Available from: http://www.ncbi.nlm.nih.gov/pubmed/15876523

12. Anderson V, Catroppa C. Recovery of executive skills following paediatric traumatic brain injury (TBI): A 2 year follow-up. Brain Inj [Internet]. 2005 Jan [cited 2014 Mar 28];19(6):45970. Available from: http://informahealthcare.com/doi/abs/10.1080/02699050400004823

13. Glang A, Ettel D, Todis B, Gordon WA, Oswald JM, Vaughn SL, et al. Services and supports for students with traumatic brain injury: Survey of state educational agencies. Exceptionality [Internet]. 2015;23(4):211-24. Available from: https://www.lib.uwo.ca/cgi- 
Accepted for publication 05/06/2019; Disability \& Rehabilitation.

bin/ezpauthn.cgi?url=http://search.proquest.com/docview/1776671084?accountid=15115

14. Kraus J, Nourjah P. The epidemiology of mild, uncomplicated brain injury. J Trauma. 1988;28(12):1637-43.

15. Hessen E, Nestvold K, Anderson V. Neuropsychological function 23 years after mild traumatic brain injury: a comparison of outcome after paediatric and adult head injuries. Brain Inj [Internet]. 2007;21:963-79. Available from:

http://ovidsp.ovid.com/ovidweb.cgi?T=JS\&CSC=Y\&NEWS=N\&PAGE=fulltext\&D=med5\&AN=1 7729049

16. McKinlay A, Grace RC, Horwood LJ, Fergusson DM, MacFarlane MR. Long-term behavioural outcomes of pre-school mild traumatic brain injury. Child Care Health Dev. 2010;36(1):22-30.

17. McKinlay a, Grace RC, Horwood LJ, Fergusson DM, Ridder EM, MacFarlane MR. Prevalence of traumatic brain injury among children, adolescents and young adults: prospective evidence from a birth cohort. Brain Inj [Internet]. 2008 Feb [cited 2014 Mar 28];22(2):175-81. Available from: http://www.ncbi.nlm.nih.gov/pubmed/18240046

18. O'Rourke C, Linden MA, Lohan M. Misconceptions about traumatic brain injury among probation services. Disabil Rehabil. Informa UK Ltd.; 2017;40(10):1119-26.

19. Perkes I, Schofield PW, Butler T, Hollis SJ. Traumatic brain injury rates and sequelae: a comparison of prisoners with a matched community sample in Australia. Brain Inj. 2011;25(February):131-41.

20. Butler T, Andrews G, Allnutt S, Sakashita C, Smith NE, Basson J. Mental disorders in Australian prisoners: A comparison with a community sample. Aust N Z J Psychiatry. 2006;40(3):272-6.

21. Ferguson PL, Pickelsimer EE, Corrigan JD, Bogner J a., Wald M. Prevalence of Traumatic Brain Injury Among Prisoners in South Carolina. J Head Trauma Rehabil. 2012;27(3):E11-20.

22. Shiroma EJ, Pickelsimer EE, Ferguson PL, Gebregziabher M, Lattimore PK, Nicholas JS, et al. Association of medically attended traumatic brain injury and in-prison behavioral infractions: A statewide longitudinal study. J Correct Heal Care. 2010;16(4):273-86.

23. Ray B, Richardson NJ. Traumatic Brain Injury and Recidivism Among Returning Inmates. Crim Justice Behav [Internet]. 2017;44(3):472-86. Available from: http://journals.sagepub.com/doi/10.1177/0093854816686631

24. O'Rourke C, Linden MA, Lohan M, Bates-Gaston J. Traumatic brain injury and co-occurring 
Accepted for publication 05/06/2019; Disability \& Rehabilitation.

problems in prison populations: A systematic review. Brain Inj. 2016;30(7):839-54.

25. McKinlay A, Albicini M. Prevalence of traumatic brain injury and mental health problems among individuals within the criminal justice system. Concussion. 2016;1-15.

26. Mccarthy J, Chaplin E, Underwood L, Forrester A, Hayward H, Sabet J, et al. Characteristics of prisoners with neurodevelopmental disorders and difficulties. J Intellect Disabil Res. 2016;60(3):201-6.

27. Hughes N, Williams H, Chitsabesan P, Davies R, Mounce L. Nobody made the connection: 2012;(October).

28. Yeates KO, Bigler ED, Dennis M, Gerhardt C a, Rubin KH, Stancin T, et al. Social outcomes in childhood brain disorder: a heuristic integration of social neuroscience and developmental psychology. Psychol Bull [Internet]. 2007 May [cited 2014 Mar 25];133(3):535-56. Available from:

http://www.pubmedcentral.nih.gov/articlerender.fcgi?artid=2841002\&tool=pmcentrez\&ren dertype=abstract

29. Pitman I, Haddlesey C, Ramos SDS, Oddy M, Fortescue D. The association between neuropsychological performance and self-reported traumatic brain injury in a sample of adult male prisoners in the UK. Neuropsychol Rehabil [Internet]. 2014;(November):1-17. Available from: http://www.tandfonline.com/doi/abs/10.1080/09602011.2014.973887

30. Beck AT, Weissman A, Lester D, Trexler L. The measurement of pessimism: The Hopelessness Scale. J Consult Clin Psychol. 1974;42(6):861-5.

31. Chang EC, D'Zurilla TJ, Maydeu-Olivares A. Assessing the dimensionality of optimism and pessimism using a multimeasure approach. Cognit Ther Res. 1994;18(2):143-60.

32. Roth, R.M., Isquith, P.K., \& Gioia G. Behavior Rating Inventory of Executive Function-Adult Version (BRIEF-A). Lutz FL: Psychological Assessment Resources, Inc.; 2005.

33. Buss AH, Perry M. The Aggression Questionnaire. J Pers. 1992;63(3):452-9.

34. Harris J a. A further evaluation of the Aggression Questionnaire: issues of validity and reliability. Behav Res Ther [Internet]. 1997 Nov;35(11):1047-53. Available from: http://www.ncbi.nlm.nih.gov/pubmed/9431736

35. Zimet GD, Dahlem NW, Zimet SG, Farley GK. The Multidimensional Scale of Perceived Social Support. J Pers Assess. 1988;52(1):30-41. 
Accepted for publication 05/06/2019; Disability \& Rehabilitation.

36. Osman A, Lamis DA, Freedenthal S, Gutierrez PM, McNaughton-Cassill M. The Multidimensional Scale of Perceived Social Support: Analyses of internal reliability, measurement invariance, and correlates across gender. J Pers Assess. 2014;96(1):103-12.

37. User Guide to Crime Statistics for England and Wales. [Internet]. Office for National Statistics. 2015 [cited 2018 Sep 14]. Available from: https://www.ons.gov.uk/ons/guidemethod/method-quality/specific/crime-statistics-methodology/user-guide-to-crimestatistics.pdf

38. Australian and New Zealand Standard Offence Classification (ANZSOC). [Internet]. Australian Bureau of Statistics. 2011 [cited 2018 Sep 14]. Available from: http://www.ausstats.abs.gov.au/ausstats/subscriber.nsf/0/5CE97E870F7A29EDCA2578A2001 43125/\$File/12340_2011.pdf

39. Böhm B, Katz-Salamon M, Smedler A-C, Lagercrantz H, Forssberg H. Developmental risks and protective factors for influencing cognitive outcome at $5 \frac{1}{2}$ years of age in very-lowbirthweight children. Dev ... [Internet]. 2002 [cited 2014 Jul 17];44:508-16. Available from: http://journals.cambridge.org/abstract_S001216220100247X

40. Grunau RE, Whitfield MF, Petrie-Thomas J, Synnes AR, Cepeda IL, Keidar A, et al. Neonatal pain, parenting stress and interaction, in relation to cognitive and motor development at 8 and 18 months in preterm infants. Pain [Internet]. International Association for the Study of Pain; 2009 May [cited 2014 Mar 24];143(1-2):138-46. Available from: http://www.pubmedcentral.nih.gov/articlerender.fcgi?artid=2836793\&tool=pmcentrez\&ren dertype=abstract

41. Brooks G, Tarling R. Boosting the Reading Levels and Attitudes of Young People who have Offended: A Review of the Evidence and the Lessons Learnt from an Evaluation of TextNow. Youth Justice [Internet]. 2012 Dec 13 [cited 2014 Aug 11];12(3):184-98. Available from: http://yjj.sagepub.com/cgi/doi/10.1177/1473225412459836

42. IBM. IBM SPSS Statistics for Windows, Version 22.0. Armonk, NY: IBM Corporation; 2013.

43. Bogner J, Corrigan JD. Reliability and predictive validity of the ohio state university TBI identification method with prisoners. J Head Trauma Rehabil. 2009;24(4):279-91.

44. Ferguson PL, Pickelsimer EE, Corrigan JD, Bogner J a, Wald M. Prevalence of traumatic brain injury among prisoners in South Carolina. J Head Trauma Rehabil [Internet]. 2012 [cited 2014 Aug 14];27(3):E11-20. Available from: http://www.ncbi.nlm.nih.gov/pubmed/22573044 
Accepted for publication 05/06/2019; Disability \& Rehabilitation.

45. Fishbein D, Dariotis JK, Ferguson PL, Pickelsimer EE. Relationships Between Traumatic Brain Injury and Illicit Drug Use and Their Association With Aggression in Inmates. 2014;

46. Chapman RCG, Hudson JM. Beliefs about brain injury in Britain. Brain Inj. 2010;24(6):797801.

47. Hux K, Schram CD, Goeken T. Misconceptions about brain injury: a survey replication study. Brain Inj [Internet]. 2006 May [cited 2014 Apr 3];20(5):547-53. Available from: http://www.ncbi.nlm.nih.gov/pubmed/16717000

48. Swift TL, Wilson SL. Misconceptions about brain injury among the general public and nonexpert health professionals: an exploratory study. Brain Inj. 2001;15(2):149-65.

49. Yuhasz JE. Misconceptions about traumatic brain injury among correctional health care professionals. J Correct Heal care [Internet]. 2013 Apr [cited 2014 Oct 27];19(2):135-43. Available from: http://www.ncbi.nlm.nih.gov/pubmed/23446874

50. Linden $\mathrm{M}$, Braiden $\mathrm{H}$, Miller S. Educational professionals' understanding of childhood traumatic brain injury. Brain Inj [Internet]. 2013 [cited 2014 Apr 3];27(1):92-102. Available from: http://informahealthcare.com/doi/abs/10.3109/02699052.2012.722262

51. Colantonio A, Kim H, Allen S, Asbridge M, Petgrave J, Brochu S. Traumatic brain injury and early life experiences among men and women in a prison population. J Correct Heal Care. 2014;

52. Simpson GK, Tate RL, Whiting DL, Cotter RE. Suicide prevention after traumatic brain injury: a randomized controlled trial of a program for the psychological treatment of hopelessness. J Head Trauma Rehabil [Internet]. 2011;26:290-300. Available from: http://ovidsp.ovid.com/ovidweb.cgi?T=JS\&CSC=Y\&NEWS=N\&PAGE=fulltext\&D=medI\&AN=21 734512

53. Safety in Custody Statistics Bulletin, England and Wales, Deaths in prison custody to March 2017, Assaults and Self-Harm to December 2016 [Internet]. Ministry Of Justice. 2017 [cited 2018 Sep 14]. Available from:

https://www.gov.uk/government/uploads/system/uploads/attachment_data/file/611187/saf ety-in-custody-statistics-q4-2016.pdf.

54. Singleton N, Farrell M, Meltzer H. Substance misuse among prisoners in England and Wales. Int Rev Psychiatry. 2003;15(1-2):150-2.

55. Fazel S, Yoon IA, Hayes AJ. Substance use disorders in prisoners: an updated systematic 
Accepted for publication 05/06/2019; Disability \& Rehabilitation.

review and meta-regression analysis in recently incarcerated men and women. Addiction. 2017;112(10):1725-39.

56. Light $\mathrm{M}$, Grant $\mathrm{E}$, Hopkins K. Gender differences in substance misuse and mental health amongst prisoners Results from the Surveying Prisoner Crime Reduction ( SPCR ) longitudinal cohort study of prisoners. Ministry of Justice Analytical Series. 2013.

57. Report on an unannounced inspection of Hydebank Wood Secure College [Internet]. Criminal Justice Inspection Northern Ireland. 2016 [cited 2018 Sep 14]. Available from: http://www.cjini.org/Thelnspections/Inspection-Reports/2016/October--December/Hydebank-Wood-Young-Offenders

58. Andrews, D. A., \& Bonta J. The psychology of criminal conduct. Routledge; 2010.

59. Squeglia LM, Jacobus J, Tapert SF. The influence of substance use on adolescent brain development. Clin EEG Neurosci. 2009;40(1):31-8.

60. West SL. Substance use among persons with traumatic brain injury: A review. NeuroRehabilitation. 2011;29(1):1-8.

61. Williams WH, McAuliffe $K$ a., Cohen $M H$, Parsonage $M$, Ramsbotham J. Traumatic Brain Injury and Juvenile Offending. J Head Trauma Rehabil [Internet]. 2015;30(2):69-74. Available from: http://content.wkhealth.com/linkback/openurl?sid=WKPTLP:landingpage\&an=00001199201503000-00001

62. Schofield $\mathrm{P}$, Butler $\mathrm{T}$, Hollis $\mathrm{S}, \mathrm{D}^{\prime}$ Este $\mathrm{C}$. Are prisoners reliable survey respondents? A validation of self-reported traumatic brain injury (TBI) against hospital medical records. Brain Inj. 2011;25(January):74-82. 
Accepted for publication 05/06/2019; Disability \& Rehabilitation.

Table 1. Characteristics of participants by group

\begin{tabular}{|c|c|c|}
\hline & $\begin{array}{l}\text { Offenders } \\
(\mathrm{N}=62)\end{array}$ & $\begin{array}{c}\text { Controls } \\
(\mathrm{N}=58)\end{array}$ \\
\hline Age, mean (SD) & $19.66(1.04)$ & $21.48(3.21)$ \\
\hline Number of convictions, mean (SD) & $24.2(26.7)$ & 0 \\
\hline Age at first conviction, mean (SD) & $14.8(2.7)$ & - \\
\hline Violent offence $\mathrm{N}(\%)$ & $43(69.4)$ & - \\
\hline TBI N (\%) & $54(87.1)$ & 33 (56.9) \\
\hline TBI Index, mean (SD) & $4.55(4.69)$ & $.69(1.48)$ \\
\hline \multicolumn{3}{|l|}{ Number of TBI N (\%) } \\
\hline $\mid 1$ & $6(11.1)$ & $17(51.5)$ \\
\hline 2 & $12(22.2)$ & $7(21.2)$ \\
\hline \begin{tabular}{l|l} 
& 3
\end{tabular} & $10(18.5)$ & $4(12.1)$ \\
\hline 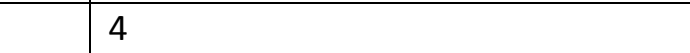 & $5(9.2)$ & $1(3)$ \\
\hline 5 & $4(7.4)$ & $1(3)$ \\
\hline $6+$ & $17(31.5)$ & $3(9)$ \\
\hline \multicolumn{3}{|l|}{ Most Severe Injury N (\%) } \\
\hline No LOC & $10(18.5)$ & $18(54.5)$ \\
\hline \begin{tabular}{l|l} 
LOC $<10 \mathrm{mins}$ \\
\end{tabular} & $22(40.7)$ & $14(42.4)$ \\
\hline $\mid$ LOC $<6$ hours & $19(35.2)$ & $1(3)$ \\
\hline \begin{tabular}{l|l|} 
LOC $>6$ hours \\
\end{tabular} & $3(5.6)$ & 0 \\
\hline \multicolumn{3}{|l|}{ Have you ever engaged in the following; $\mathrm{N}(\%)$} \\
\hline \begin{tabular}{l|l} 
& Physical/Threatened assault
\end{tabular} & $50(80.6)$ & $5(8.6)$ \\
\hline \begin{tabular}{l|l} 
& Dangerous acts endangering persons
\end{tabular} & 39 (62.9) & $1(1.7)$ \\
\hline \begin{tabular}{l|l} 
Robbery (including attempted)
\end{tabular} & $35(56.5)$ & $1(1.7)$ \\
\hline \begin{tabular}{l|l} 
& Sexual assault and related offences
\end{tabular} & $1(1.6)$ & 0 \\
\hline Murder and related offences & $8(12.9)$ & 0 \\
\hline \begin{tabular}{l|l} 
& Abduction/harassment
\end{tabular} & $11(17.7)$ & 0 \\
\hline \multicolumn{3}{|c|}{$\begin{array}{l}\text { Age at first engagement in risky behaviour, mean } \\
\text { (SD) }\end{array}$} \\
\hline Alcohol consumption & $13.98(2.09)$ & $16.2(2.01)$ \\
\hline Cigarette use & $12.79(2.71)$ & $17.2(1.68)$ \\
\hline
\end{tabular}


Accepted for publication 05/06/2019; Disability \& Rehabilitation.

\begin{tabular}{|c|c|c|}
\hline Illegal drug use & $14.03(2.22)$ & $18.3(1.71)$ \\
\hline Sex & $14.33(1.72)$ & $17.6(1.47)$ \\
\hline \multicolumn{3}{|l|}{ Highest qualification N (\%) } \\
\hline Primary school & $31(50)$ & 0 \\
\hline GCSE/equivalent* & $13(21)$ & 0 \\
\hline Apprenticeship & $4(6.5)$ & $1(1.7)$ \\
\hline Certificate/Diploma & $11(17.7)$ & $4(6.9)$ \\
\hline A-levels/equivalent $^{+}$ & $2(3.2)$ & $36(62.1)$ \\
\hline University Degree & $1(1.6)$ & $16(27.6)$ \\
\hline Postgraduate Degree & 0 & $1(1.7)$ \\
\hline \multicolumn{3}{|l|}{ Maternal Education N (\%) } \\
\hline Primary school & $5(8.1)$ & $3(5.2)$ \\
\hline GCSE/equivalent* & $21(33.9)$ & $16(27.6)$ \\
\hline Apprenticeship & $2(3.2)$ & 0 \\
\hline Certificate/Diploma & $7(11.3)$ & $4(6.9)$ \\
\hline A-Level/equivalent $^{+}$ & $5(8.1)$ & $9(15.5)$ \\
\hline University Degree & $4(6.5)$ & $20(34.5)$ \\
\hline Postgraduate Degree & $1(1.6)$ & $4(6.9)$ \\
\hline Unknown & $17(27.4)$ & $2(3.4)$ \\
\hline Low SES N (\%) & $35(77.8 \%)$ & $23(41 \%)$ \\
\hline Drug Abuse N (\%) & $50(80.6)$ & $4(6.9)$ \\
\hline Alcohol Abuse N (\%) & $34(54.8)$ & $6(10.3)$ \\
\hline Mental Illness N (\%) & $37(58.1)$ & $4(6.9)$ \\
\hline
\end{tabular}

*GCSE refers to the general certificate in secondary education qualification normally taken at age 16 years; ${ }^{+} A$-level refers to Advanced-level qualifications normally taken at age 18 years. 
Accepted for publication 05/06/2019; Disability \& Rehabilitation.

Table 2. Total and subscale scores for offender and control participants with TBI

\begin{tabular}{|l|l|c|c|c|c|}
\hline \multicolumn{2}{|l|}{} & $\begin{array}{c}\text { Offenders with } \\
\text { TBI (N=54) }\end{array}$ & $\begin{array}{c}\text { Controls with } \\
\text { TBI (N=33) }\end{array}$ & $p$ & $95 \%$ Cl \\
\hline \multicolumn{2}{|l|}{} & Mean (SD) & Mean (SD) & & \\
\hline \multicolumn{2}{|l|}{ Behavioural Regulation Index } & $66.01(9.35)$ & $51.33(9.77)$ & $<.001$ & -19.08 to -11.76 \\
\hline \multicolumn{2}{|l|}{ Shift } & $18.35(2.68)$ & $14.45(3.6)$ & $<.001$ & -5.20 to -2.86 \\
\hline & Emotion & $13.01(2.44)$ & $10.09(2.58)$ & $<.001$ & -4.18 to -2.31 \\
\hline & Self-monitor & $18.94(3.39)$ & $14.93(3.55)$ & $<.001$ & -5.51 to -2.89 \\
\hline Aggression & $13.7(2.36)$ & $10.52(2.76)$ & $<.001$ & -4.27 to -2.38 \\
\hline & Physical & $101.19(14.86)$ & $69.39(13.89)$ & $<.001$ & -38.31 to -27.17 \\
\hline & Verbal & $34.56(5.83)$ & $20.81(7)$ & $<.001$ & -16.30 to -11.50 \\
\hline & Anger & $18.11(3.23)$ & $13.73(3.42)$ & $<.001$ & -5.31 to -2.75 \\
\hline & Hostility & $24.59(4.48)$ & $15.55(4.35)$ & $<.001$ & -11.42 to -8.02 \\
\hline Hopelessness & $23.93(5.27)$ & $19.3(4.81)$ & $<.001$ & -7.02 to -3.14 \\
\hline Perceived Social Support & $64.68(13.01)$ & $68.36(12.5)$ & .167 & - \\
\hline & Family & $21.38(7.08)$ & $24.55(3.84)$ & .049 & - \\
\hline & Friends & $20.08(5.62)$ & $22.24(5.04)$ & .053 & - \\
\hline & Special person & $23.22(4.93)$ & $21.58(5.77)$ & .201 & - \\
\hline
\end{tabular}

